\title{
What is Sexual Harassment? It Depends on Who Asks! Framing Effects on Survey Responses
}

\author{
MIRTA GALESIC ${ }^{1}$ and ROGER TOURANGEAU ${ }^{1,2 *}$ \\ ${ }^{1}$ Joint Program in Survey Methodology, University of Maryland, USA \\ ${ }^{2}$ Survey Research Center, University of Michigan, USA
}

\begin{abstract}
SUMMARY
We examine the impact of the framing of the survey request-the description of the survey's sponsor and topic - on respondents' answers and describe three mechanisms that may underline such effects. Respondents can try to be relevant and cooperative and provide answers they see as the most useful; they can use the sponsorship and other elements of the survey presentation to help them understand ambiguous questions; and they may find it easier to recall instances of events related to the survey presentation. In a study that framed the survey in two different ways-one sponsored by a feminist organisation fighting against sexual harassment and the other sponsored by a neutral research institute-we found significant differences in the ways people understood and answered questions about sexual harassment. We show that all of the three mechanisms we distinguish might have affected the results. Copyright (C) 2007 John Wiley \& Sons, Ltd.
\end{abstract}

Many studies have demonstrated that the context of an item can influence the answers that respondents give. These context effects can originate during various components of the response process (see Chapter 7 of Tourangeau, Rips, \& Rasinski, 2000, for a review). For example, prior items about one topic (say, poverty in America) can alter what respondents retrieve as they answer questions about a related topic later on (welfare spending), affecting their answers to the later questions (e.g. Tourangeau, Rasinski, Bradburn, \& D'Andrade, 1989a,b). The earlier items are said to 'prime' the retrieval of certain considerations related to the later items. Another mechanism leading to context effects involves respondents relying on earlier items to provide an interpretative framework for an item about some unfamiliar or ambiguous issue. For example, Tourangeau and Rasinski (1988) found that when a question about an obscure piece of legislation (the Monetary Control Bill) followed a series of questions about inflation, some respondents seemed to infer the bill was measure against inflation. Similarly, Strack, Schwarz, and Wänke (1991) showed that German respondents reported very different views about an undefined 'educational contribution' when that item followed one about college tuition in the US than when it followed an item about government aid to students in Sweden. Apparently, the respondents inferred what the 'educational contribution' was a payment from them rather than a payment to them based on the prior item. 
In most of studies on context effects in surveys, context has been defined quite narrowly, usually as the preceding few questions in the questionnaire. The impact of the broader survey frame, or the way the survey is presented to the respondents in terms of its name, sponsor, topic and stated purpose, has rarely been investigated. There are only a few exceptions. In a study by Presser, Blair, and Triplett (1992), the respondents to a telephone survey about a political issue were told that the survey sponsor was either a neutral institution (the University of Maryland) or a newspaper with a well-known position on the issue (The Washington Post). Respondents who were told the newspaper was sponsoring the study gave answers that were significantly more in line with the paper's position than the respondents who thought the study was sponsored by the university. Norenzayan and Schwarz (1999) reported a study in which University of Michigan students first read about an actual mass murder case and then tried to explain the murderer's motives. One group got the questionnaire printed on the letterhead of a fictitious 'Institute of Personality Research', while the other group got it on the letterhead of the 'Institute of Social Research'. As Schwarz and Norenzayan predicted, when the researcher was identified as a personality psychologist, the respondents provided more explanations related to the personality of the murderer and fewer explanations related to his social circumstances. The opposite was true for respondents who thought the researcher was a social scientist-they gave more situational than personality-related explanations for the murder.

Finally, Smith, Schwarz, Roberts, and Ubel (2006) conducted a survey of patients from the Delaware Valley area. They were invited to participate either in a survey of 'people who have Parkinson's disease' or a survey of 'people who live in the eastern United States', and asked about their life satisfaction (first) and about the satisfaction with their health (second question). The correlations between the life satisfaction and the health-satisfaction were higher when the survey was introduced as a study of people with Parkinson's disease $(r=0.63)$ than when it was introduced as a study of general population $(r=0.34)$. When the order of questions was reversed in a subsequent study, the correlations between the lifeand health-satisfaction were equally high regardless of the introduction (0.47 and 0.56); this result was consistent with the authors' view that a health-related introduction has effects similar to those of prior health-related questions.

There are several possible mechanisms that may lead to such effects of the survey frame on respondents' answers. The survey presentation may affect the respondents' decision to participate in a survey and the resulting difference in non-response bias may produce differences in results. Other mechanisms relate specifically to the way the respondents, once they agree to take part in the survey, process and answer the questions. Three such mechanisms through which survey frame may affect the answers are triggering cooperative conversational norms, providing an interpretive framework for the survey items, and priming relevant beliefs.

The first mechanism is based on Grice's (1989) cooperative principle - the unstated assumption in everyday conversations that participants should make their contributions useful. In a survey, this principle implies that the respondent's task is to determine the point of each question and to provide the information the question is really seeking (not necessarily the information that it literally requests). The perceived intent of the question is likely to be affected by the survey's presentation. An example from the General Social Survey (GSS), a national attitude survey conducted by NORC since 1972, seems to illustrate this process. One of the standard questions is 'Are there any situations you can imagine in which you would approve of a policeman striking an adult male citizen'? Although it is easy to envision situations in which a policeman would be fully justified in 
using force-for example in subduing an escaping criminal-more than $30 \%$ of the respondents answered 'No' to this question in the 1998 GSS (see http://webapp.icpsr.umich.edu/GSS). These respondents do not seem to take the question literally, but base their answers on their reading of the question's underlying intent, perhaps inferring that the item is intended to tap their views about police brutality.

A second possible mechanism that could underlie the effects of survey presentation is that the presentation of the survey provides an interpretive framework that helps respondents resolve ambiguities about the meaning or scope of the questions. Most concepts include both clear instances and borderline cases; for instance, a chair is clearly a piece of furniture, but it is harder to say whether a floor lamp should be counted as furniture as well (for an application of this principle in a survey setting, see Schober \& Conrad, 1997). The sponsorship and other clues from the framing of the survey request may help respondents decide how to deal with such borderline instances. For example, Tourangeau and McNeeley (2003) argue that the trappings of the National Crime Victimization Survey (NCVS) - the survey's name, the fact that it is conducted by the US Bureau of the Census on behalf of the Bureau of Justice Statistics, the use of advance letters printed on government stationary-are likely to convey to the respondents that the topic of the survey is crimes narrowly construed. This may have contributed to some controversial estimates derived from NCVS data, such as estimates of the prevalence of rape and defensive gun use. Critics have characterised these estimates as being much too low (e.g. Kleck, 1997, Kleck \& Gertz, 1995; Koss, 1992, 1993, 1996). Kleck (1997) reviews estimates from than 13 surveys on the frequency of instances of the defensive gun use; the estimates vary from as low as 65000 instances use per year to as high as 3.5 million. A similarly disparate set of figures surrounds the question of how many women are rape victims each year. The NCVS, National Women's Study (NWS), and National Violence Against Women Survey (NVAWS) estimates for 1992 range from 140000 to 680000 (Lynch, 1996) and from 269000 to 876000 in 1995 (Bachman, 2000; see also Fisher, 2004 and Fisher \& Cullen, 2000). Respondents in the NCVS are likely to construe the questions narrowly, omitting borderline incidents and atypical victimisations. In surveys that are framed differently (e.g., the National Women's Survey or the National Self-Defense Survey), respondents may adopt the opposite strategy, casting a broader net and making every effort to report questionable instances. Our point is not that the NCVS estimates are biased, but simply that the topic and the sponsor may change how respondents interpret the questions, perhaps in unintended ways. Every survey presents the request to participate in some way and the manner of presentation may affect how respondents interpret the questions.

The third way in which survey frame can affect answers is by reminding respondents of things they would not have otherwise recalled. This phenomenon is well known in basic psychological studies on implicit memory: for example participants in a typical experiment would be more likely to complete a word fragment '_o_se' with 'mouse' than with 'house' or 'moose' if they were even briefly exposed to the word 'mouse' before the task. This would happen even when the participants were not aware of seeing that word before (see Schacter, 1987, for a review of many relevant studies). Similar phenomena are well documented in studies on attitudes, moods and social cognition in general (e.g. Bargh, 1994; Devine, 1989; Schwarz \& Clore, 1983). As we already noted, such priming effects are also common in the literature on context effects. For example in one of the developmental studies for the National Crime Study, respondents who had first answered a series of questions designed to assess their fear of crime reported more victimisations than their counterparts who got the victimisation items first (Cowan, Murphy, \& Wiener, 1978). The fear-of-crime items apparently facilitated recall of victimisations. 
The aim of this study is to document framing effects on survey responses and to illustrate the mechanisms underlying these effects. We asked questions about different workplace situations, some of which might be interpreted as sexual harassment, within two different survey frames: one stressing the researcher's connection with a feminist organisation dedicated to the issue of sexual harassment; and the other portraying the researchers as neutral on the issue of sexual harassment. We hypothesise that all three mechanisms described above will affect the results. First, we predict that the respondents who got the feminist frame will, in an attempt to be relevant, tend to under-report experiencing situations that are not sexual harassment and that are therefore less likely to be related to the researchers' goals. Second, because the survey presentation offers an interpretive cue for ambiguous items, we expect that the respondents in the feminist frame will be more likely to interpret ambiguous situations as instances of sexual harassment. This will also be reflected in the degree to which they report being bothered by even relatively benign situations. Third, due to priming, we expect that the respondents in the feminist frame will tend to recall and report experiencing more sexually harassing situations than the respondents in the neutral frame. Like the fear-of-crime questions in the National Crime Survey, the framing of the survey will prime the retrieval of otherwise inaccessible incidents.

\section{METHOD}

\section{Participants}

The participants were recruited from two sources. The first was SSI's Survey Spot panel, an opt-in Web panel of almost one million persons who have signed up online to receive survey invitations in return for a chance to win cash prizes in a sweepstakes. A total of 29772 respondents received email invitations to take part in the survey, and 1361 did so, for a response rate of $4.6 \%$. The second was AOL Opinion Place, which draws its participants through banner advertisements and rewards them with American Airlines miles. This way of recruiting does not allow for calculation of traditional response rates; 1254 respondents were recruited from an unknown number of invitees.

As there were no significant differences between the results obtained in the two groups of respondents, we present only the analyses based on all 2615 respondents. Of these, $55.2 \%$ were women and $44.8 \%$ men; $21.1 \%$ were under 35 years of age, $39.8 \%$ were between 35 and 54 years of age and $39.2 \%$ was 55 years old or older; $23.8 \%$ had high school education or less, $40.0 \%$ had some college and $36.2 \%$ had completed college.

\section{Questions}

We asked questions about 16 situations that can happen at a workplace. Some of the situations were taken from several questionnaires about sexual harassment (including ones by Foulis \& McCabe, 1997; Reilly, Lott, \& Gallogly, 1986; and Kadela Collins, 2003)—for example, 'A co-worker brushes up against another co-worker's body' and 'A manager/ supervisor puts an arm around the shoulder of an employee'. Other items described situations that can be considered workplace bullying, but not sexual harassment; for example: 'A manager/supervisor yells at an employee' and 'A co-worker spreads rumours about another employee'. These items were adapted from questionnaires and descriptions of bullying available at several leading US and UK websites dedicated to victims of 
bullying (www.bullyinginstitute.org, www.bullyonline.org, and www.workplacebullying. co.uk). ${ }^{1}$ The complete list of the 16 situations we asked about is listed in the Appendix.

We asked three different questions about each of the 16 situations. The first question was about how often the respondent had experienced the situations: 'For each situation, please indicate how often it happens in your current job during a typical month. If you are not currently working, please answer the questions based on your experiences at your last job'. (Respondents who never worked were skipped out of these questions.) The response scale had seven points, with the end points labelled Never and All the time. The second question asked about respondents' reactions to each of the situations: 'How much would it bother you if these situations happened where you were working'? Again, the respondents answered on a seven-point scale, with the end points labelled Not at all and Very much. The third question asked about respondents' interpretation of each of the situations: 'How likely is that each of these situations represents sexual harassment in the workplace'? The response scale again had seven points, ranging from Not at all likely to Very likely.

\section{Procedure}

This experiment was embedded in a Web survey about a range of life-style and health issues. After completing approximately one half of a 20-minute questionnaire, the respondents were randomly assigned to one of two framing conditions. One group was told that the sponsor of the next set of questions was a feminist organisation, the Women Against Sexual Harassment; the other group was told that the sponsor was a research organisation called the Work Environment Institute. In addition, the questions received by the first group appeared under the title 'Sexual Harassment Survey', while those received by the second group were titled 'Work Atmosphere Survey'. Figure 1 presents screenshots of the survey descriptions received by each group.

A total of 2598 respondents were administered the frequency items, which asked them how often they experienced each situation at work; $3 \%$ of the respondents reported they had never worked and were not asked any of these questions. To reduce respondent burden, we asked each respondent either the second set of questions about how much each situation would bother them (1306 respondents got these items) or the third set asking whether the situation represented sexual harassment (1292 respondents) for the 16 situations. This split was orthogonal to the framing manipulation. For each set of questions, the 16 situations were presented in grids. Each grid contained four questions in randomised order and each grid was presented on a separate screen.

The study was approved by the University of Michigan Institutional Review Board. At the end of the survey, the respondents were informed that the organisations were fictitious and used 'to see whether knowing the sponsor of a set of questions can affect people's interpretation of the questions'. The respondents were also told that their answers will not be shared with anyone outside of the University of Michigan research team.

\section{RESULTS}

Item non-response rates for each set of questions were relatively small. Of the respondents who answered at least one of the frequency questions, 95.0\% answered all 16; and

\footnotetext{
${ }^{1}$ In a small pretest on six employees of different organisations, the situations taken from the questionnaires on sexual harassment were judged to 'represent sexual harassment' in the workplace by 3.1 respondents, on average, while the situations taken from the bullying questionnaires were judged as such by only 0.4 respondents on average.
} 


\section{$1^{\text {st }}$ group ("Feminist frame"):}

\section{SEXUAL HARASSMENT SURVEY}

The following questions are taken from a survey about work atmosphere. We are asking these questions on behalf of the Women Against Sexual Harassment Organization. The Women Against Sexual Harassment Organization is a leading feminist organization dedicated to empowering women and fighting sexual harassment.

\section{$2^{\text {nd }}$ group ("Neutral frame"):}

\section{WORK ATMOSPHERE SURVEY}

The following questions are taken from a survey about work atmosphere. We are asking these questions on behalf of the Work Environment Institute. The Work Environment institute is a research center dedicated to studying factors that influence work satisfaction and productivity.

Figure 1. Survey framing manipulation

the corresponding figures for the second and the third sets of questions were 94.3 and $91.6 \%$.

We present the overall results for the three sets of questions and then examine differences across the individual items. We looked for interactions between the experimental variables and the sex, age and education of the respondents and found no interactions. ${ }^{2}$ We present only the overall results here.

\section{Frequency of encountering different situations}

The two situations that were said to be most frequently encountered in the workplace were, under both frames: 'A co-worker conducts loud personal conversations in the presence of other employees' (overall average frequency rating on a seven-point scale was 4.06) and 'A co-worker does not share important information with colleagues' (3.88). Under both frames, the least frequently encountered situations were 'A co-worker sends an email of a nude person to another co-worker' (average rating 1.71) and 'A co-worker kisses another co-worker on the cheek' (2.72). Average ratings for all 16 items on all three scales are shown in the Appendix.

Differences in the reported frequency of experiencing the 16 situations between the respondents from the feminist and neutral frames are shown in Figure 2. Although the

\footnotetext{
${ }^{2}$ We also conducted analyses of the main effects of sex, age, and education on responses. Younger respondents (the up to 35 and 35-54 age groups) reported significantly higher overall frequency of encountering the situations depicted by our items than older respondents $(55+; F(2,2324)=36.16, p<0.01)$. Respondents with high school and some college also reported higher frequency of encountering these situations than the respondents with college education $(F(2,2324)=5.09, p<0.01)$. Women were more bothered than men by most of the situations $(F(1,1191)=56.61, p<0.01)$, and respondents of 35 and more years of age were more bothered than respondents under $35(F(2,1191)=8.41, p<0.01)$. There were no main effects of sex, age or education on judgments of the likelihood that the situations constituted sexual harassment.
} 
Comments they looked nice

Brushes up a person's body

Arm around shoulder

Stares

Sends nude pics

Yells

Kisses on the cheek

Invites for drinks

Comments physical appearance

Insults

Takes things

Spreads rumors

Non-work related calls

Witholds information

Loud personal conversations

Sets impossible deadlines

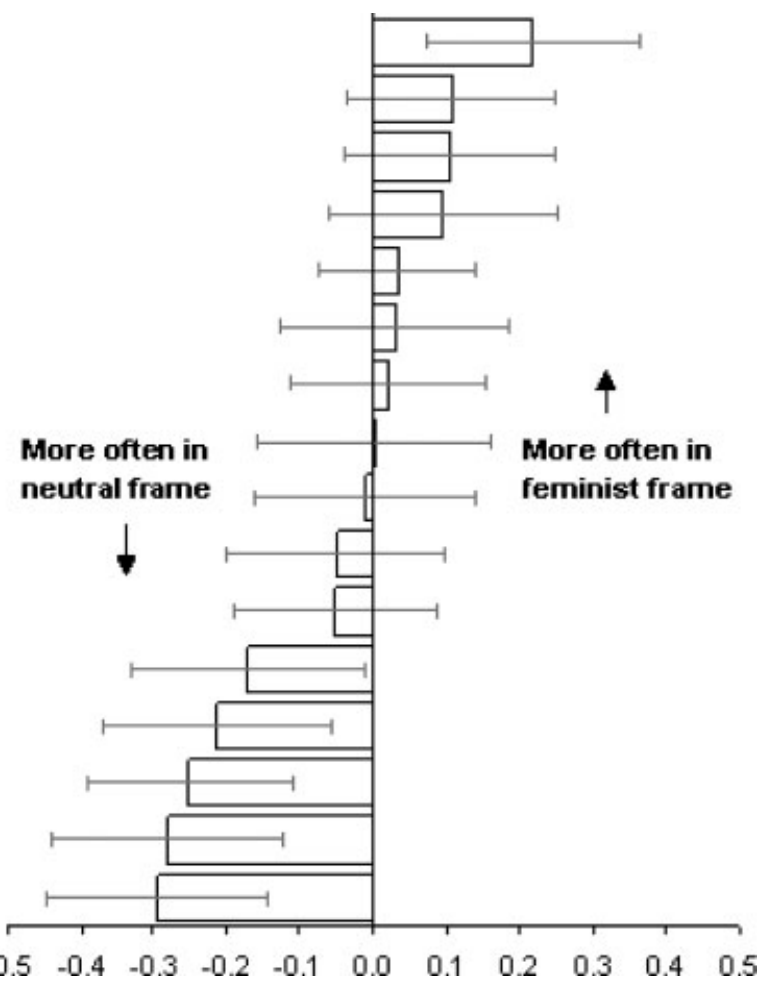

Figure 2. Differences between feminist and neutral frame in mean answers to the question: '.. please indicate how often it happens in your current job during a typical month' (on a seven-point scale) and 95\% confidence intervals

overall difference between the two groups was not statistically significant across all 16 items $(F(1,2409)<1, \mathrm{~ns})$, the differences for 6 of the individual items were significant by $t$-tests; these can be seen in Figure 2 as the items whose $95 \%$ confidence intervals do not include zero. In addition, there was a significant item-by-treatment effect $(F(15$, $2409)=6.89, p<0.01)$, indicating that the difference in the ratings by framing group varied by item.

As shown in Figure 2, the respondents who got the feminist frame reported encountering most of the neutral situations (such as 'A manager/supervisor sets impossible deadlines for an employee' and 'A co-worker conducts loud personal conversations in the presence of other employees') less often than the respondents who got the neutral frame, but they reported the situations that more clearly involve sexual harassment (such as 'A manager/ supervisor comments to employees that they looked nice in their clothing') more often than the respondents who got the neutral frame.

\section{Reaction to the situations}

The situations that received the highest ratings on the second set of questions ('How much would it bother you if these situations happened where you were working'?) were, in both frames, 'A co-worker takes things that belong to another employee without asking' (overall average rating was 6.08 on a seven-point scale) and 'A co-worker spreads rumours about 
another employee' (5.94). The least bothersome situations were, in both frames, 'A co-worker approaches another co-worker about having a drink outside of work' (2.66) and 'A manager/supervisor comments to employees that they looked nice in their clothing' (2.96).

Overall, the differences between the ratings of the 16 situations given by the respondents who got the feminist and neutral frames were not statistically significant $(F(1,1236)<1$, $\mathrm{ns})$. The degrees of freedom for the error term reflect the fact that only about half the respondents in each framing group got this set of items. However, the overall item-by-treatment effect was again significant $(F(15,1236)=3.24, p<0.01)$, indicating that the differences between the two framing groups varied significantly by item.

More specifically, most of the situations that had at least the potential to be seen as sexual (such as 'A manager/supervisor comments to employees that they looked nice in their clothing' and 'A co-worker approaches another co-worker about having a drink outside of work') - that is situations that might involve sexual harassment depending on the circumstances-were rated as more bothersome by those who got the feminist frame than by those who got the neutral frame (Figure 3).

\section{Likelihood that situation is sexual harassment}

The situations judged as most likely to be sexual harassment were, under both frames, 'A co-worker sends an email of a nude person to another co-worker' (overall mean rating of

\section{Comments they looked nice \\ Invites for drinks \\ Sends nude pics}

Arm around shoulder

Non-work related calls

Loud personal conversations

Brushes up a person's body

Kisses on the cheek

Insults

Takes things

Spreads rumors

Comments physical appearance

Sets impossible deadlines

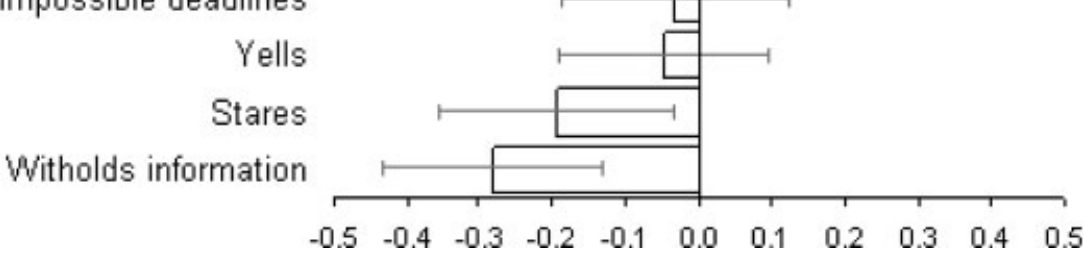

Figure 3. Differences between feminist and neutral frame in answers to the question: 'How much would it bother you if these situations happened where you were working'? (on a seven-point scale) and $95 \%$ confidence intervals 
4.87) and 'A co-worker brushes up against another co-worker's body' (4.57). The situations judged least likely to be sexual harassment were 'A co-worker does not share important information with colleagues' (2.16), 'A co-worker takes things that belong to another employee without asking' (2.52) and 'A manager/supervisor sets impossible deadlines for an employee' (2.53).

There was a significant and consistent difference between the ratings given by the respondents under the two frames (Figure 4). Those who got the feminist frame rated all 16 situations as more likely to represent sexual harassment than those who got the neutral frame, and these differences were significant for 12 of the individual items. This trend is reflected in a significant between-subject effect $(F(1,1187)=12.21, p<.01)$, but a non-significant item-by-treatment difference $(F(15,1187)=1.66$, ns). As shown in Figure 4, the differences between the two frames were always in the same direction and significant for two-thirds of the individual items.

\section{Item-level analysis}

As we have seen, for the first two sets of questions, the impact of the survey framing depended on the item. Thus, we attempted to look at the results at the item level. In Figure 5, all 16 situations are shown in a grid in which the horizontal axis represents differences between the feminist and neutral frame groups in the mean frequency of

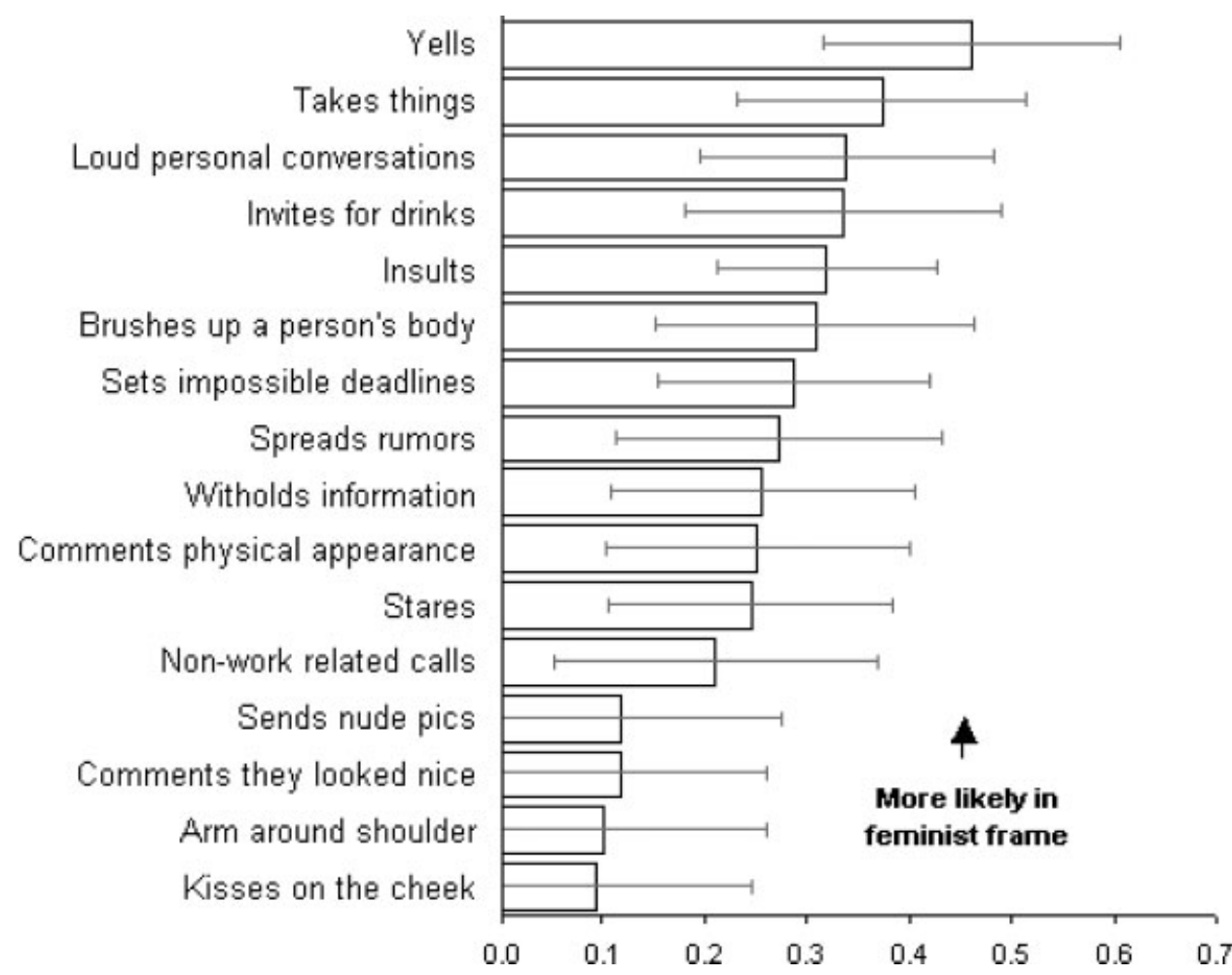

Figure 4. Differences between feminist and neutral frame in answers to the question: 'How likely is that each of these situations represents sexual harassment in the workplace'? (on a seven-point scale) and $95 \%$ confidence intervals 


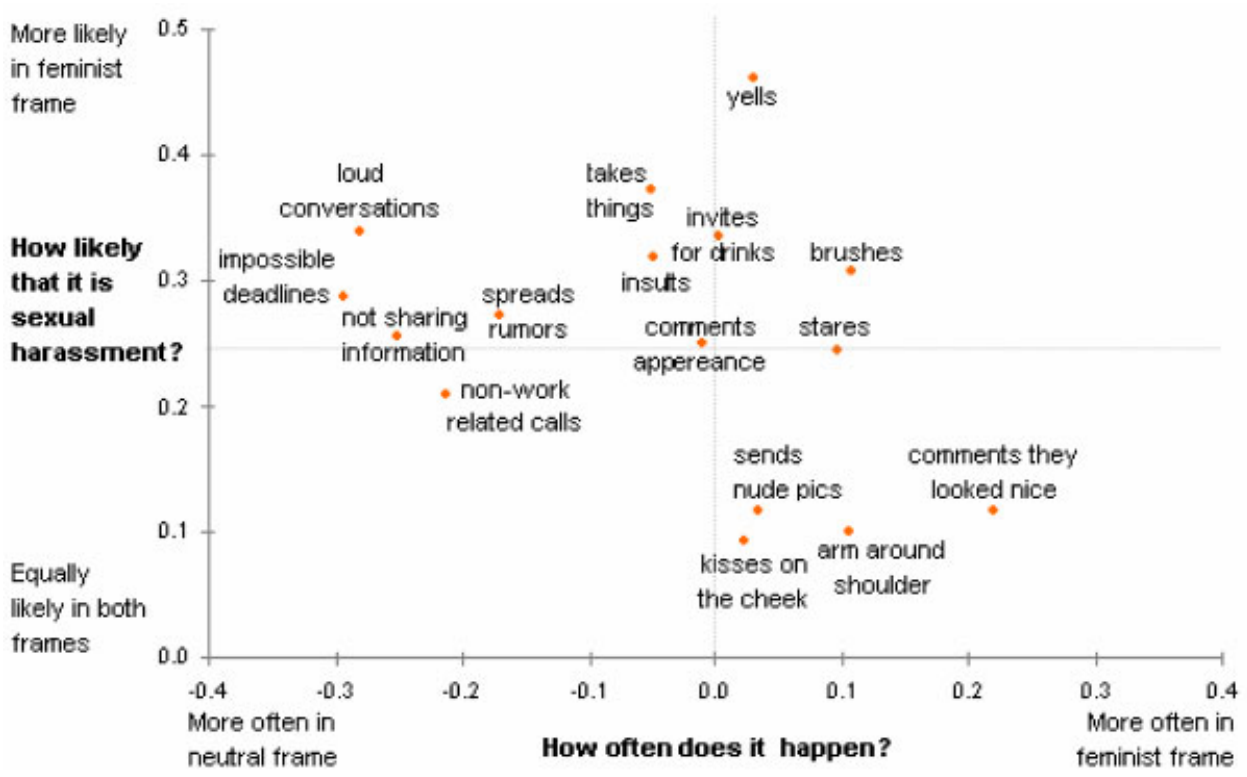

Note: The axes represent differences between the average evaluations given in the feminist and the neutral frame. Each tick mark represents 0.1 -point difference on 7 -point scales.

Figure 5. Item-level analysis: frequency of encountering a situation vs. likelihood that it constitutes sexual harassment.

encountering these situations at one's workplace and the vertical axis represents differences in the mean ratings of the likelihood that a situation is a sexual harassment.

Items further on the right along the horizontal axis at Figure 5 are those that were reported as occurring more often under the feminist frame; and items further on the left along that axis were reported as occurring more often under the neutral frame. Items towards the bottom of the vertical axis are considered likely to be sexual harassment in both frames; and items towards the top are more ambiguous situations, that can be perceived as sexual harassment or benign depending on the circumstances.

Most of the items in Figure 5 fall either in the top left or in the bottom right quadrant. The items in the bottom right quadrant are the less ambiguous situations, those considered likely to be sexual harassment under both frames. These situations were reported as occurring more often under the feminist frame. By contrast, the items in the top left quadrant are more neutral situations that were more prone to frame-related interpretations: they were much more likely to be called sexual harassment in the feminist frame. At the same time, these situations were more often reported in the neutral frame.

\section{DISCUSSION}

In this experiment, we manipulated the presentation, or framing, of a survey on sexual harassment. The respondents were presented with a list of situations that could arise at a workplace, including some situations that were likely to represent sexual harassment and 
others that were unlikely to represent sexual harassment. For each of the situations, the respondents indicated how often it happened at their workplace, how much it would bother them if it did happen and how likely it was that the situation represented sexual harassment. For one group of the respondents, we titled the survey 'Sexual Harassment Survey' and described it as sponsored by a feminist group dedicated to the fight against sexual harassment. Another group of the respondents received the same questions within a survey titled 'Work Atmosphere Survey', whose sponsor was described as a neutral research centre dedicated to studying factors that influence work satisfaction and productivity.

As predicted, the experimental manipulation affected respondents' answers. Respondents who got the feminist frame for the survey were more likely to report the situations that clearly involved sexual harassment at their workplace, were more bothered by ambiguous situations that might or might not represent sexual harassment, and were more likely to interpret even relatively benign situations as representing sexual harassment.

In addition, the pattern of results offers some support to the three hypothesised mechanisms through which the survey frame can affect the answers. First, the situations that were unlikely to be sexual harassment (such as 'A manager/supervisor sets impossible deadlines for an employee' and 'A co-worker conducts loud personal conversations in the presence of other employees') were reported less often in the feminist group than in the neutral group (Figure 2). This suggests that the respondents in both groups were trying to follow Grice's maxim of relevance by reporting fewer situations that appeared unrelated to the survey topic and more of the situations that clearly fit the topic.

Second, the group who got the feminist frame interpreted most of the situations as significantly more likely to be sexual harassment than those who got the neutral frame (Figure 4). In addition, they rated the situations that potentially involved sexual harassment as more bothersome on average (Figure 3 ) than the neutral group did. The presentation of the survey seemed to provide respondents with an interpretative framework that they used when trying to interpret ambiguous situations (such as 'A co-worker approaches another co-worker about having a drink outside of work').

Finally, the feminist group reported witnessing somewhat more situations that were likely to involve sexual harassment (such as 'A manager/supervisor comments to employees that they looked nice in their clothing') than the neutral group. It may be that the context of the survey (sexual harassment) aided them in recalling instances of such behaviours.

It is important to note that these effects, although significant and consistent, are very small—only 0.12 points on a seven-point scale for the question about frequency of experiencing different situations, 0.11 for the question about how bothersome these situations would be, and 0.26 for the question about the likelihood that the situation represents sexual harassment. Therefore, we do not suggest that questions presented within a potentially biasing framing necessarily produce strongly biased results, but only that the framing might be one of several sources of survey errors (for a discussion of errors stemming from imperfect questionnaires on sexual harassment, see Gutek, Murphy, \& Douma, 2004). The value of this study lies more in indicating the presence of a problem and in documenting the different mechanisms through which the survey frame can influences answers.

\section{CONCLUSION}

The framing of the survey request - the survey's title, topic, stated purpose and sponsor-can affect the respondents' answers. We describe three mechanisms that might 
underlie this effect: the framing may trigger the norm of cooperation, it may provide interpretive framework for the questions, and it may facilitate the recall of certain type of situations. We found a significant influence of survey frame on the results, as well as evidence of all three mechanisms underlying this effect in a survey on sexual harassment. Topics that are not well defined and that can be interpreted in different ways-sexual harassment may be one such topic (cf. Gutek et al., 2004)—-may be particularly prone to these kinds of influences. Researchers are advised to take into account survey framing when comparing results of different studies on the same or similar topics. Every survey presents itself to the respondents in some terms; these terms can affect both who responds and how they answer the questions.

\section{REFERENCES}

Bachman, R. (2000). Violence against women: Synthesis of research for criminal justice policymakers. Washington, DC: U.S. Department of Justice, National Institute of Justice.

Bargh, J. A. (1994). The four horsemen of automaticity: Awareness, efficiency, intention, and control in social cognition. In R. S. Wyer, Jr, \& T. K. Srull (Eds.), Handbook of social cognition (2nd ed., pp. 1-40). Hillsdale, NJ: Erlbaum.

Cowan, C. D., Murphy, L. R., \& Weiner, J. (1978). Effects of supplemental questions on victimization estimates from the National Crime Survey. In Proceedings of the American Statistical Association Section on Survey Research Methods 1978 (pp. 277-282). Alexandria, VA: American Statistical Association.

Devine, P. G. (1989). Stereotypes and prejudice: Their automatic and controlled components. Journal of Personality and Social Psychology, 56, 5-18.

Fisher, B. S., \& Cullen, F. T. (2000). Measuring the sexual victimization of women: Evolution, current controversies, and future research. Criminal Justice, 4, 317-390.

Fisher, B. S. (2004). Measuring rape against women: The significance of survey questions. DC: National Institute of Justice, Office of Justice Programs, U.S. Department of Justice, NCJ 199705.

Foulis, D., \& McCabe, M. (1997). Sexual harassment: Factors affecting attitudes and perceptions. Sex Roles, 37, 773-798.

Grice, H. P. (1989). Studies in the way of words. Cambridge, MA: Harvard University Press.

Gutek, B. A., Murphy, R. O., \& Douma, B. (2004). A review and critique of the Sexual Experiences Questionnaire (SEQ). Law and Human Behavior, 28, 457-482.

Kadela Collins, K. (2003). Sexual harassment in the workplace-An online survey. Retrieved 12/1/ 2005 from http://www.mimh.edu/shw/

Kleck, G., \& Gertz, M. (1995). Armed resistance to crime: The prevalence and nature of self-defense with a gun. Journal of Criminal Law and Criminology, 86, 150-187.

Kleck, G. (1997). Targeting guns: Firearms and their control. NY: Aldine de Gruyter.

Koss, M. (1992). The underdetection of rape: A review of prevalence research methods. Journal of Social Issues, 48, 63-75.

Koss, M. (1993). Detecting the scope of rape: A review of prevalence research methods. Journal of Interpersonal Violence, 8, 198-222.

Koss, M. (1996). The measurement of rape victimization in crime surveys. Criminal Justice and Behavior, 23, 55-69.

Lynch, J. P. (1996). Clarifying divergent estimates of rape from two national surveys. Public Opinion Quarterly, 60, 410-430.

Norenzayan, A., \& Schwarz, N. (1999). Telling what they want to know: Participants tailor causal attributions to researchers' interests. European Journal of Social Psychology, 29, 1011-1020.

Presser, S., Blair, J., \& Triplett, T. (1992). Survey sponsorship, response rates, and response effects. Social Science Quarterly, 73, 699-702.

Reilly, M. E., Lott, B., \& Gallogly, S. M. (1986). Sexual harassment of university students. Sex Roles, 15, 333-358. 
Schacter, D. L. (1987). Implicit memory: History and current status. Journal of Experimental Psychology: Learning, Memory and Cognition, 13, 501-518.

Schober, M. F., \& Conrad, F. G. (1997). Does conversational interviewing reduce survey measurement error? Public Opinion Quarterly, 61, 576-602.

Schwarz, N., \& Clore, G. L. (1983). Mood, misattribution, and judgments of well-being, informative and directive functions of affective states. Journal of Personality and Social Psychology, 45, 513-523.

Smith, D. M., Schwarz, N., Roberts, T. R., \& Ubel, P. A. (2006). Why are you calling me? How study introductions change response patterns. Quality of Life Research, 15, 621-630.

Strack, F., Schwarz, N., \& Wänke, M. (1991). Semantic and pragmatic aspects of context effects in social and psychological research. Social Cognition, 9, 111-125.

Tourangeau, R., \& McNeeley, M. (2003). Measuring crime and crime victimization: Methodological issues. Washington, D.C.: National Research Council.

Tourangeau, R., \& Rasinski, K. (1988). Cognitive processes underlying context effects in attitude measurement. Psychological Bulletin, 103, 299-314.

Tourangeau, R., Rasinski, K., Bradburn, N., \& D'Andrade, R. (1989a). Belief accessibility and context effects in attitude measurement. Journal of Experimental Social Psychology, 25, 401-421.

Tourangeau, R., Rasinski, K., Bradburn, N., \& D'Andrade, R. (1989b). Carryover effects in attitude surveys. Public Opinion Quarterly, 53, 495-524.

Tourangeau, R., Rips, L. J., \& Rasinski, K. (2000). The psychology of survey response. Cambridge: Cambridge University Press. 


\section{APPENDIX}

Table A1. List of all situations and their average evaluations, across both frames

\begin{tabular}{|c|c|c|c|}
\hline Situation & $\begin{array}{l}\text { How often } \\
\text { encountered? }\end{array}$ & $\begin{array}{c}\text { How } \\
\text { bothersome? }\end{array}$ & $\begin{array}{l}\text { How likely } \\
\text { sexual } \\
\text { harassment? }\end{array}$ \\
\hline \multicolumn{4}{|l|}{ From questionnaires on sexual harassment: } \\
\hline $\begin{array}{l}\text { A co-worker approaches another co-worker about } \\
\text { having a drink outside of work }\end{array}$ & 3.68 & 2.66 & 3.24 \\
\hline $\begin{array}{l}\text { A co-worker brushes up against another } \\
\text { co-worker's body }\end{array}$ & 2.63 & 4.74 & 4.57 \\
\hline $\begin{array}{l}\text { A co-worker kisses another co-worker on } \\
\text { the cheek }\end{array}$ & 2.27 & 3.74 & 3.97 \\
\hline $\begin{array}{l}\text { A co-worker makes non-work related calls } \\
\text { to another co-worker's home }\end{array}$ & 3.38 & 3.55 & 3.34 \\
\hline $\begin{array}{l}\text { A co-worker makes remarks about other } \\
\text { co-worker's physical appearance }\end{array}$ & 3.48 & 4.19 & 3.85 \\
\hline $\begin{array}{l}\text { A co-worker sends an email of a nude person } \\
\text { to another co-worker }\end{array}$ & 1.71 & 5.27 & 4.87 \\
\hline $\begin{array}{l}\text { A manager/supervisor comments to employees } \\
\text { that they looked nice in their clothing. }\end{array}$ & 3.26 & 2.96 & 3.52 \\
\hline $\begin{array}{l}\text { A manager/supervisor puts an arm around the } \\
\text { shoulder of an employee }\end{array}$ & 3.04 & 3.48 & 3.70 \\
\hline \multicolumn{4}{|l|}{ From questionnaires on bullying: } \\
\hline $\begin{array}{l}\text { A co-worker conducts loud personal conversations } \\
\text { in the presence of other employees }\end{array}$ & 4.06 & 4.68 & 2.75 \\
\hline $\begin{array}{l}\text { A co-worker does not share important } \\
\text { information with colleagues }\end{array}$ & 3.88 & 5.56 & 2.16 \\
\hline A co-worker insults another co-worker & 3.57 & 5.50 & 2.83 \\
\hline $\begin{array}{l}\text { A co-worker spreads rumours about } \\
\text { another employee }\end{array}$ & 3.75 & 5.94 & 3.48 \\
\hline A co-worker stares at another co-worker & 3.57 & 3.40 & 3.11 \\
\hline $\begin{array}{l}\text { A co-worker takes things that belong to } \\
\text { another employee without asking }\end{array}$ & 2.57 & 6.08 & 2.52 \\
\hline $\begin{array}{l}\text { A manager/supervisor sets impossible } \\
\text { deadlines for an employee }\end{array}$ & 3.62 & 5.24 & 2.53 \\
\hline A manager/supervisor yells at an employee & 3.34 & 5.57 & 2.65 \\
\hline
\end{tabular}

Note: The exact text of the questions is given in Methods section. All answers were given on a seven-point scale. 